\title{
ULTRASOUND EXAMINATION AND LOCALIZATION OF THE SCIATIC NERVE
}

Hugo A Nova MD, Vincent WS Chan MD, Sherif Abbas MD, Colin JL McCartney, MBChB, Anahi Perlas MD, DaQuan Xu MD

\section{AFFILIATION:}

Department of Anesthesia and Pain Management, Toronto Western Hospital, University Health Network, University of Toronto, 399 Bathurst Street, Toronto, Ontario M5T 2S8

\section{INTRODUCTION}

Few studies have examined the use of ultrasound for sciatic nerve localization. ${ }^{1,2,3}$ We evaluated the usefulness of low frequency ultrasound in identifying the sciatic nerve at three locations in the lower extremity and in guiding needle advancement to target before nerve stimulation.

\section{METHODS}

After IRB approval and informed consent, 15 volunteers underwent sciatic nerve examination using a curved ultrasound probe in the range of 2-5 MHz and a Philips-ATL 5000 unit in the gluteal, infragluteal and proximal thigh regions. Thereafter, an insulated block needle was advanced inline with the ultrasound beam to reach the nerve target, which was further confirmed by electrical stimulation. The quality of sciatic nerve images, ease of needle to nerve contact, threshold stimulating current and the resultant motor response were recorded.

\section{RESULTS}

The sciatic nerve was successfully identified in the transverse view as a solitary hyperechoic structure on ultrasound in all of the three regions examined. The target nerve was visualized easily (within 10 seconds by 2 independent investigators) in 13/15 subjects. The nerve was successfully contacted by the block needle and electrically stimulated in all cases with a threshold current of $0.42 \pm 0.12$ (mean $\pm \mathrm{SD}$ ) eliciting plantar or dorsi-flexion in all subjects.

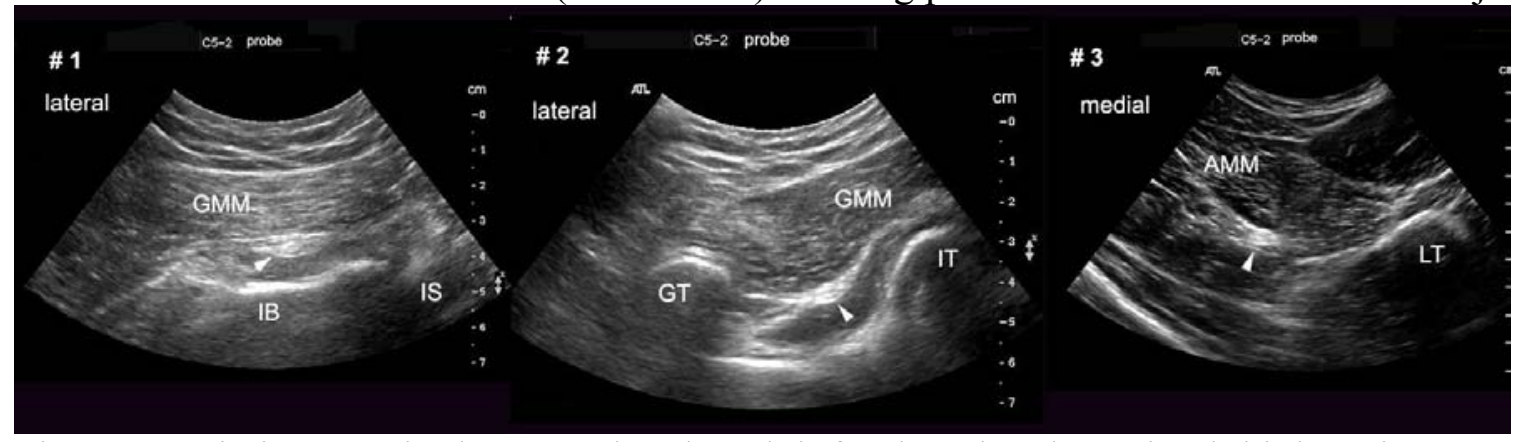

Figure 1. Sciatic nerve is shown at the gluteal, infragluteal and proximal thigh regions.

\section{CONCLUSIONS}

Our preliminary data show that low frequency curved 2-5 MHz ultrasound probe provides good quality sciatic nerve imaging in the gluteal, infragluteal and proximal thigh locations.

Ultrasound assisted sciatic nerve localization is potentially valuable for clinical sciatic nerve blocks.

\section{REFERENCES}

1. Reg Anesth Pain Med. 29:130-4

2. Anesth Analg. 97:1300-2

3. Reg Anesth Pain Med. 28:479-82 